\title{
Insights into autosomal dominant polycystic kidney disease by quantitative mass spectrometry-based proteomics
}

\author{
Britta Diedrich $^{1,2}$ • Jörn Dengjel ${ }^{1,3}$
}

\begin{abstract}
Autosomal dominant polycystic kidney disease (ADPKD) is a common monogenetic disorder that is caused by mutations in the genes PKD1 and PKD2 encoding polycystin-1 and polycystin-2, respectively. Polycystin-1 and -2 form a complex, interact with several proteins involved in signal transduction and localize to discrete subcellular positions, most importantly the primary cilium. Whereas the causative mutations leading to ADPKD are known, the underlying deregulated cellular pathways are not well understood. In the current review, we introduce state-of-the-art mass spectrometry (MS)based proteomic techniques and summarize their use in kidney and ADPKD research. Proteomic profiling approaches, the elucidation of ADPKD-relevant proteinprotein interactions and the regulation of posttranslational modifications are included. We also discuss the use of MS-based methods for ADPKD prognosis, diagnosis and disease monitoring by using protein- and peptide-based biomarkers.
\end{abstract}

Keywords Genetic disease · Kidney · Mass spectrometry · Proteomics $\cdot$ Biomarker

Jörn Dengjel

joern.dengjel@unifr.ch

1 Department of Dermatology, Medical Center-University of Freiburg, 79104 Freiburg, Germany

2 Present address: Agilent Technologies, Hewlett-Packardstrasse 8, 76337 Waldbronn, Germany

3 Department of Biology, University of Fribourg, Chemin du Musée 10, CH-1700 Fribourg, Switzerland

\section{Autosomal dominant polycystic kidney disease}

The human kidney is divided into two major regions: the outer renal cortex and the inner medulla. Cortex and medulla can be separated into renal lobes containing a pyramid-shaped part of the medulla of which the tip, the papilla, reaches into a minor calyx. Several minor calyces form major calyces finally yielding the renal pelvis from which the ureter emanates. Numerous small filtering units called nephrons, which are the basic urine-producing renal functional structures, span cortex and medulla and are each subdivided into the actual filter, namely the glomerulus situated in the cortex, followed by the tubule. The glomeruli filter blood, whereas cells and macromolecules are retained and generate the primary urine. The tubules reabsorb the majority of the filtrate, minerals and water and excrete additional waste products into the collecting ducts, which span the cortex and medulla and open out into the calyx at the papilla releasing urine.

Autosomal dominant polycystic kidney disease (ADPKD) is the most common inherited kidney disease (1:400-1:1000 births) and the fourth most single cause of end-stage renal disease (ESRD; Collins et al. 2012). It is characterized by the development of kidney cysts that generally initiate from a tubule (Grantham 2008). Cysts fill with fluid and expand in size leading to a four- to eight-fold expansion of kidney volume and significant loss of renal function over time (Roitbak et al. 2004). Mutations in the genes PKD1 and PKD2 encoding the integral membrane glycoproteins polycystin-1 (PC-1) and polycystin-2 (PC-2) cause ADPKD. PC-2, a calcium-permeable cation channel and its regulatory subunit PC-1 form a complex that interacts with additional proteins involved in signal transduction. Both proteins localize to discrete subcellular positions, most importantly the primary cilium (Newby et al. 2002; Ong and Harris 2005). The significance of the two proteins is reflected by the extensive 
available scientific literature covering them. In a recent bioinformatics study, over 24 million PubMed records concerning cardiovascular, cerebral, hepatic, renal, pulmonary and intestinal research fields were screened, and a small number of proteins that were ubiquitously investigated across fields was identified (Lam et al. 2016). To characterize organ/ disease-specific marker proteins, the authors normalized the system-specific publication counts of a protein by its total publication count. The top target protein in the renal system, in both human and mouse, turned out to be PC-1, followed by PC-2, underlining their importance and disease relevance.

In ADPKD, intracellular calcium levels are reduced and renal cAMP levels are elevated, possibly leading to the observed hyper-proliferative phenotype. Increased cAMP levels may also stimulate increased fluid secretion into cyst lumens. Cell proliferation is thought to be further potentiated by increased MTOR kinase activity attributable to perturbed cilia function (Boehlke et al. 2010). Interestingly, polycystins appear to inhibit a cilia-dependent signaling pathway that promotes rapid cyst growth (Ma et al. 2013). Hence, current treatments are aimed at reducing (1) cAMP-levels, (2) cell proliferation and (3) fluid secretion (Chang and Ong 2012). To reduce cell proliferation, the goal of several therapeutic strategies is the reduction of MTOR activity. This approach has been corroborated by results obtained in rat models of PKD in which rapamycin treatment led to decreased cyst and kidney volume and improved renal function (Huber et al. 2011). However, in contrast to the results obtained in animal studies, the first placebo-controlled clinical trials in ADPKD involving the rapamycin analogs sirolimus (Perico et al. 2010; Serra et al. 2010) and everolimus (Walz et al. 2010) gave different conflicting outcomes. In two trials, MTOR inhibition slowed the increase of total kidney volume, whereas in one trial, no effect was found indicating that disease stage, duration of treatment and clinical readout have to be carefully re-examined. Although MTOR activity clearly contributes to cyst growth in human ADPKD, the therapeutic potential of MTOR inhibition has still to be explored. Next to MTOR, additional kinases have been investigated for their role in ADPKD. A trial with the broad-spectrum tyrosine kinase inhibitor (TKI) bosutinib (Winter et al. 2012), which showed promising results in PKD rodent models (Sweeney et al. 2008), is still ongoing and estimated to finish in 2018. Further kinase inhibitors, such as the non-selective BRAF inhibitor sorafenib and activatiors of AMPK, such as metformin, are being tested pre-clinically (Chang and Ong 2012). Interestingly, the G-protein coupled receptor Vasopressin V2 receptor stimulating adenylate cyclase and regulating urine concentration in tubules and collecting ducts has also emerged as a promising drug target halting cyst growth (Gattone et al. 2003). In a placebo-controlled trial, tolvaptan, a receptor antagonist increasing water excretion, slowed the increase of kidney volume; however, it also led to increased adverse effects (Torres et al. 2012; see also discussion in Rinschen et al. 2014a). Thus, whereas the importance of several signaling pathways in PKD has been shown, the functional implications of their activity in vivo are only poorly understood.

New technical developments may help in addressing open biological and medical questions in ADPKD and may pave the way for new causal therapies. Mass spectrometry (MS)based proteomics is such a technique that can be employed to address basic research questions and applied medical problems. It can also be used as a diagnostic method to monitor disease progression with the help of biomarkers. In the current review, we introduce peptide and protein-based state-of-theart MS assays and summarize their use in ADPKD and kidney research.

\section{Quantitative MS-based proteomics}

Whereas a proteome is defined as the entire protein content of a given cell, tissue, organ, or organism at a specific time point, the term proteomics is nowadays used to define technically challenging, large-scale analyses of proteins (Aebersold and Mann 2016; Lossl et al. 2016). These can be detailed analyses of single proteins or, indeed, studies addressing an entire proteome. MS is by far the most popular and developed analytical method for performing such proteomic studies. Two basic MS-based proteomic approaches can be discriminated depending on the nature of the analyte: peptide- and proteinbased analyses (Fig. 1). The most common approach is the "bottom-up proteomics" analysis of peptides. Proteins are extracted from samples of interest and proteolytically digested into peptides prior to MS analysis. Although this approach increases sample complexity, it is extremely popular because of its easy automation (Aebersold and Mann 2016). As physicochemical properties of peptides are fairly similar regardless of the tissue- or protein-of-interest, standard MS methods can be applied to diverse biological samples. In contrast, "topdown proteomics" analysis characterizes entire proteins. This approach allows, among others, the study of posttranslational modification (PTM) crosstalk (Catherman et al. 2014). However, because of the unique characteristics of each protein, top-down proteomics is technically rather challenging and experimental conditions have to be adopted for each protein-of-interest or each protein group-of-interest.

MS as such is only a semi-quantitative method as the signal intensity detected by a mass spectrometer depends on the ionization properties of proteins/peptides to be analyzed. Hence, signal intensities of distinct proteins/peptides cannot be directly compared with each other. To allow truly quantitative MS studies, relative and absolute quantification approaches have been developed (Bakalarski and Kirkpatrick 2016). Several depend on distinct stable isotope labels, commonly employing ${ }^{13} \mathrm{C}$ and ${ }^{15} \mathrm{~N}$, which allow quantification in single $\mathrm{MS}$ 
Fig. 1 Mass spectrometry (MS)-based proteomic workflows. MS is employed to study proteins and peptides. Top-down protein analysis (left) preserves information about posttranslational modification (PTM) crosstalk and dependency. Its implementation is challenging as chromatography and ionization parameters have to be adjusted for each (group of) protein(s). Bottom-up peptide analysis (right) depends on the proteolytic generation of peptides. Trypsin is the most commonly used protease in proteomic research. The technical implementation of bottom-up proteomics is easier as the physicochemical properties of distinct peptides are more similar compared with those of proteins. However, PTM crosstalk information is lost and sample complexity is increased ( $L C$ liquid chromatography, $m$ mass, $P L R P-S$ polystyrene-divinylbenzene, $R P$ reversedphase, $z$ elementary charge). Figure produced by using Servier Medical Art (www.servier.com)

analyses. Labels can be introduced chemically after tissue/cell lysis or metabolically by organismal or cellular labeling approaches (Fig. 2). Both approaches have pros and cons and have been discussed in detail in recent reviews (Bakalarski and Kirkpatrick 2016). Next to label-based approaches, label-free quantification algorithms have been developed that allow an almost as accurate quantification (Tyanova et al. 2016). Whereas they are easy to implement, they increase MS analysis time, as each sample has to be analyzed separately. Notably, parallel sample processing is absolutely critical for obtaining accurate quantification results by label-free approaches.

Proteomic experiments can also be discriminated by discovery and targeted MS analyses. In kidney research, discovery-driven experiments are still in the majority: experiments are performed to generate new biological/medical knowledge without a priori knowledge of all protein targets. On the contrary, targeted MS analyses are employed to study a set of pre-defined proteins/peptides under specific biological/ medical conditions or over time. Targeted approaches, like all facets of selected reaction monitoring (SRM; Bourmaud et al. 2016), may also be employed in prognostic and diagnostic settings to follow disease biomarkers. Targeted proteomic experiments are in concurrence to classic immunobiological approaches, i.e., enzyme-linked immunosorbent assays (ELISAs). Importantly, being equally as sensitive and specific as antibody-based analyses, they are independent of matching antibody/antigen pairs (Zahedi et al. 2014). Up to now, the knowledge of the proteotyptic peptides of potential biomarker candidate proteins to be used in targeted MS analyses has been limited, making the development of targeted proteomic assays time- and labor-intensive. Two recent impressive large-scale studies have defined protein-specific peptides for the entire human proteome to be used in targeted MS approaches (Kusebauch et al. 2016; Matsumoto et al. 2016). With these resources available, the development of targeted MS assays should be less time-consuming boosting their implementation in basic and translational research and in clinical diagnostics.

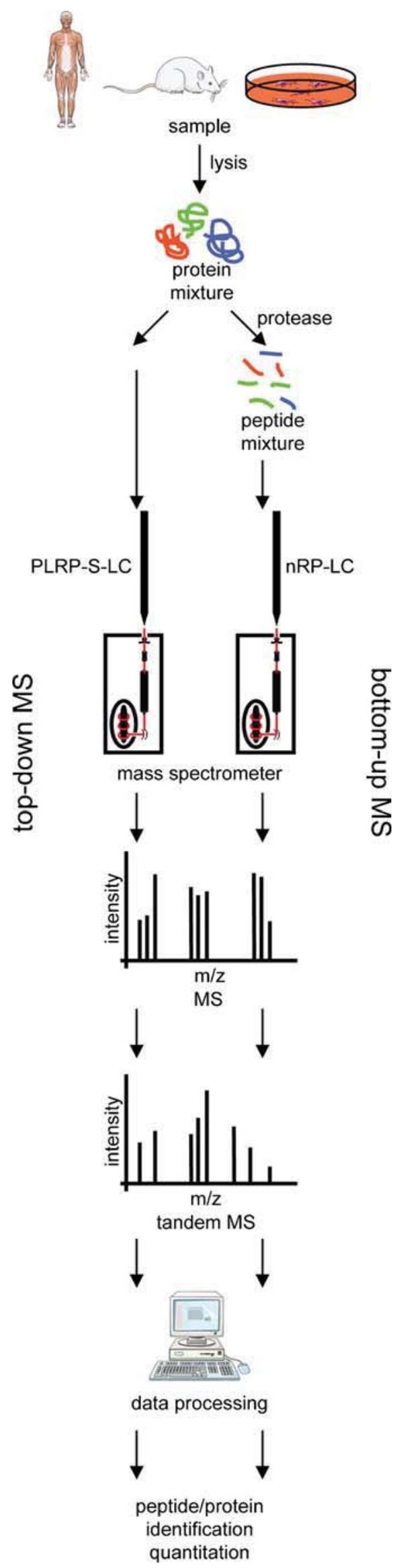


a

metabolic labeling

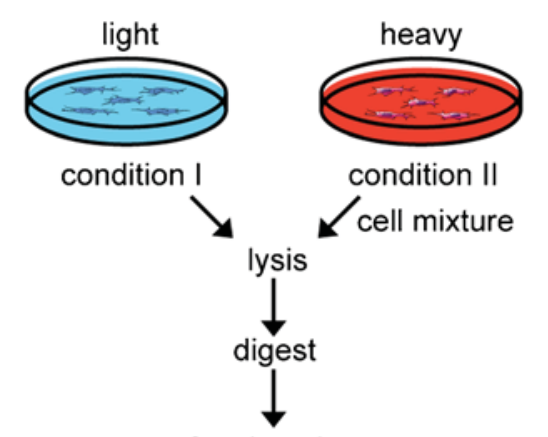

fractionation
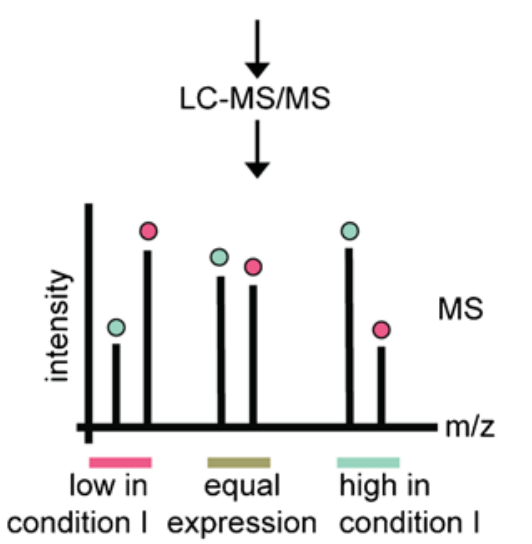

relative quantification by LC-MS and identification of peptides by LC-MS/MS b

chemical labeling

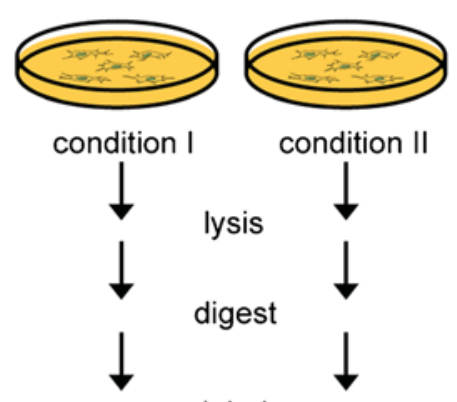

○ label

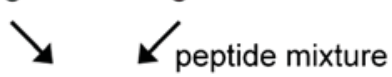

fractionation
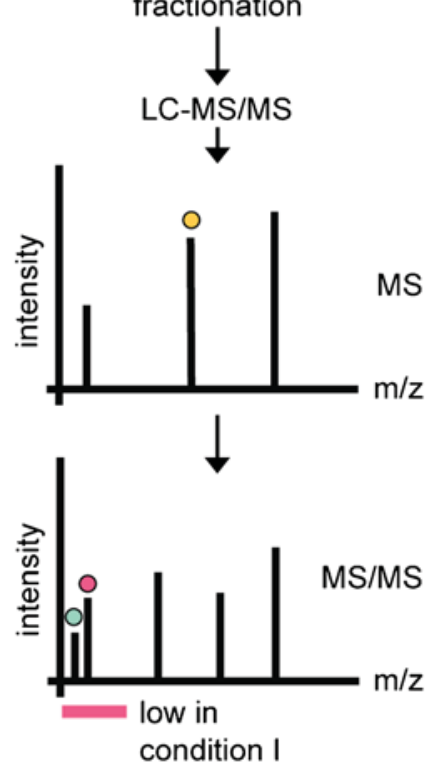

relative quantification

and identification of

peptides by LC-MS/MS
C label-free
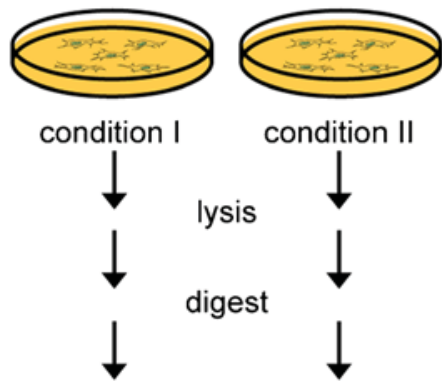

fractionation

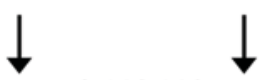

LC-MS/MS
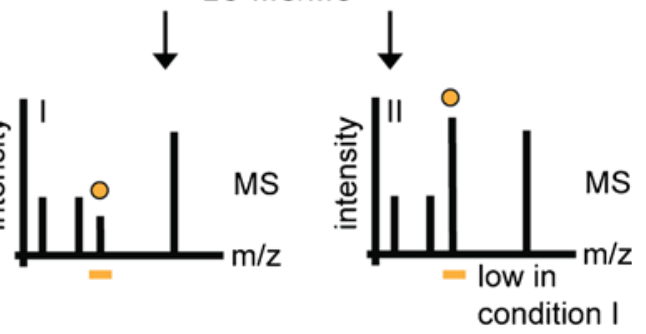

relative quantification by LC-MS and identification of peptides by LC-MS/MS
Fig. 2 Quantitative MS-based proteomic approaches. A Metabolic labeling. The most well-known metabolic labeling approach is stable isotope labeling by amino acids in cell culture (SILAC). Commonly, ${ }^{13} \mathrm{C}$ - and ${ }^{15} \mathrm{~N}$-labeled arginine and lysine variants are employed. Compared with other labeling methods, samples can be combined early in the experimental procedure minimizing quantification errors. Colored dots in spectra represent the respective SILAC label. $B$ Chemical labeling. The most commonly used chemical labeling approaches are TMT (Tandem Mass Tag) and iTRAQ (Isobaric Tags for Relative and Absolute Quantitation) labeling by, which up to eight samples can be compared. A labeling

\section{The kidney proteome}

Inventories or atlases of proteins are indispensable tools for researchers. They define a ground state and highlight those proteins that might be present and, thus, potentially detectable in specific systems or under specific conditions. Accordingly, considerable resources have been expended in defining organand cell-type-specific proteomes. Maps of human tissue experiment performed at the peptide level is depicted. However, proteins can also be labeled. In contrast to the other labeling approaches, TMTand ITRAQ-based approaches rely on quantification in the MS/MS mode. The peptide marked by a yellow dot is selected for fragmentation. In the MS/MS fragment spectrum, distinct labels become observable and quantifiable (marked by colored dots). $C$ Label-free quantification. In labelfree quantification, each sample is analyzed separately and quantification is performed at the MS level. Colored dots mark a differentially distributed peptide. Figure produced by using Servier Medical Art (www. servier.com)

proteomes have been published as part of the Human Protein Atlas (Fagerberg et al. 2014; Uhlen et al. 2015). Several subproteomes such as the secretome, the membrane proteome and the druggable proteome have been assayed by transcriptomic expression analysis in complex tissue homogenates, including various cell types, in concert with the precise localization of the proteins by microarray-based immunohistochemistry. The kidney proteome has also been defined in 
this enormous dataset. Transcriptomic data imply that $65 \%$ of all human genes is expressed in the kidney. Of these, 325 genes show an increased expression level in the kidney compared with other human tissues; they include several aquaporins, solute carriers and NPHS2 (podocin). Respective proteins are part of the glomerular filtration diaphragm and transport proteins responsible for the excretion and adsorption of various small molecules and water in distinct parts of the tubule. As in all of the analyzed tissues, the elevated genes in the kidney can be clearly linked to the overall function of the organ. Moreover, MS-based analyses have been performed to map the kidney proteome. Next to organ-centric studies (Magdeldin et al. 2014; Wilhelm et al. 2014), cell-typespecific proteomes for tubular and for glomerular cells have been defined (Boerries et al. 2013; Konvalinka et al. 2013).

To improve our understanding of proteome alterations under pathological conditions, methods have been developed to analyze formalin-fixed paraffin-embedded (FFPE) tissues specimens by MS analyses (Ostasiewicz et al. 2010; for detailed technical information, see also Gustafsson et al. 2015; Maes et al. 2013). FFPE tissue specimens represent preserved clinical material that is a unique protein source for studying human disorders and for the identification of disease biomarkers. Their wide distribution and resolution of tissue holds great promise. As the concentration of low-abundant disease-related proteins is significantly higher inside the diseased compared with the non-affected tissue, tissue-based proteomics of FFPE sections is often preferred when insights into disease-related processes are required (Tanca et al. 2014). In particular, no standard procedures are generally used for the freezing and storage of fresh samples $\left(-20{ }^{\circ} \mathrm{C},-80{ }^{\circ} \mathrm{C}\right.$, or liquid nitrogen) and thus, the analysis of FFPE samples is thought to be an appropriate alternative to the analysis of freshly frozen material (Bronsert et al. 2014).

Unique features of MS-based proteomic studies compared with any other "omic" approach are the unbiased large-scale analyses of protein-protein interactions (Diedrich et al. 2017) and of PTMs of proteins (Rigbolt et al. 2014) giving insights into the activity and regulation of specific proteins. As PTM analyses are often based on single peptide identifications, they are more error-prone than protein studies. To identify potential sources of wrongly assigned PTMs in kidney disease proteomics, formalin-induced alterations in FFPE samples compared with freshly frozen samples of human kidney tissue have been characterized in a label-free proteomic approach (Zhang et al. 2015). In an open modification search, the authors found +12 , $+14,+16,+30$ and +58 Da mass shifts on various amino acid residues of peptides isolated from FFPE samples, shifts that were not present in freshly frozen samples. The major modification found was a $+14 \mathrm{Da}$ additive representing a methylation of lysine residues. Luckily, the overall number of peptides containing a formalin-induced methylation was in an acceptable low range $(2-6 \%)$. However, since methylations on histone lysines often play a crucial role in the regulation of gene expression and chromatin remodeling, this formalininduced artifact should be taken into account when studying methylation events in renal FFPE specimens (Zhang et al. 2015).

One of the most widely analyzed PTMs is protein phosphorylation (Rigbolt and Blagoev 2012), which may influence protein localization, activation, interaction and stability. In 2014, the first atlas of phosphorylated residues of murine glomerular proteins employing a label-free phosphoproteomic approach was generated. Phosphopeptides were enriched from freshly isolated murine glomeruli by using immobilized metal ion affinity chromatography (IMAC) to gain a comprehensive dataset of in vivo phosphorylations. Phosphorylations of podocyte-specific proteins were further analyzed and synaptopodin was identified as the protein carrying the highest number of phosphorylation sites. Most proline-directed phosphorylation sites were observed in their C-terminal region, which is one of the major interaction sites of $\alpha$-actinin- 4 regulating podocyte cytoskeletal dynamics. Proline-directed kinases such as ERK, CDK1, -2 , or -5 may be involved in the modulation of the podocyte cytoskeleton. Moreover, previously undescribed phosphorylation sites on the slit diaphragm proteins KIRREL, NPHS1, NPHS2, CD2AP and TRPC6 were discovered. The sites were found exclusively in acidic amino acid motifs indicating that acidic kinases such as casein kinases are responsible (Rinschen et al. 2014b). To prioritize and identify physiologically meaningful phosphorylation sites, a cross-species comparability of glomerular phosphorylation sites between cow and rat was performed (Rinschen et al. 2015). The acidic site motifs were indeed conserved in NPHS1 and CD2AP and further evidence considering the C-terminal phosphorylation of NPHS2 was gathered. NPHS2 phosphorylation regulated its affinity to both CD2AP and NPHS1. CD2AP was described to interact with PC-2, being expressed at lower levels in renal tubular epithelial cells of the mature kidney, while being up-regulated during kidney differentiation (Lehtonen et al. 2000). Thus, the interaction of PC-2 and CD2AP might also be regulated phosphorylation-dependently. However, this mechanism awaits experimental proof.

\section{Proteomic insights into ADPKD}

As early as 1996, mice deficient for $\alpha 3 \beta 1$ integrin were found to show abnormal lung and kidney development with decreased branching of the medullary collecting ducts, although the numbers of nephrons remained normal. As a consequence, the proximal tubules became microcystic and glomerular development was affected by wider capillary lumina (Kreidberg et al. 1996). In a follow-up study, the same group 
demonstrated a role of $\alpha 3 \beta 1$ integrin in sequestering mouse CBL into the Golgi apparatus, preventing MET from becoming ubiquitinated and resulting in hyperactive MTOR on a $P k d 1^{-/}$background (Qin et al. 2010). Whereas the first two studies were performed based on classic mouse genetics and cell biology, the same group observed an interesting result concerning $\alpha 3 \beta 1$ integrin glycosylation by employing MS. $\mathrm{PkdI}^{+/+}$and $\mathrm{Pkd}^{-/}$mouse kidney epithelial cells were isolated and an anti- $\alpha 3$ integrin immunoprecipitation was performed, followed by LC-MS/MS analysis at the peptide level (Zhang et al. 2014). Several types of glycans were found attached to the four known sites within the C-terminal domain of the $\alpha 3$ integrin subunit. Asn937 exclusively showed the high-mannose type, whereas Asn971 showed either the complex or the hybrid type of glycan trees. No difference in abundance of glycosylation was detected between knock-out or wild-type cells at these sites. However, at sites Asn925 and Asn928, the authors found significant site-specific differences in glycan structure between $\mathrm{Pkdl}^{+/+}$and $\mathrm{Pkd}^{/-}$cells. An unusual disialic acid glycan was identified in $\mathrm{Pkd}^{-/}$cells; this was not present in wild-type cells. Both sites were glycosylated with glycans of the hybrid-type. Sialic acid is a negatively charged acidic sugar creating a local negative charge on membranes and may cause repulsion between cells. The authors hypothesized that the conformation of integrin receptors might be altered because of the unusual glycosylation pattern containing more negatively charged glycans, which may further influence receptor recognition and ligand-binding affinity. In ADPKD, $\alpha 3 \beta 1$ integrin can lose contact with the extracellular matrix (ECM) and disialic-acid-supported repulsion of tubular cells might contribute to cyst formation. Whereas this hypothesis still has to be established, the study nicely highlights that MS-based proteomics can be employed in an unbiased way to generate new disease-relevant hypotheses.

PC-2 was also identified as being glycosylated and respective sites were mapped by MS (Hofherr et al. 2014). Glycosylation and the trimming of the glycan tree by glucosidase II was critical for efficient surface expression of PC-2. Interestingly, mutations in genes encoding glucosidase II family members have been linked to autosomal dominant polycystic liver disease. Thus, independent groups have identified altered glycosylation patterns on ADPKD-relevant proteins and an altered glycan structure might contribute to ADPKD pathology.

By analyzing protein-protein interactions by MS, PC-1 was identified to interact with the trimeric G-protein subunit $\mathrm{G} \alpha 12$ via its cytoplasmatic tail and $P d k 1$ deletion led to increased activity of $G \alpha 12$ (Yuasa et al. 2004). By using MDCK cells that inducibly overexpressed $\mathrm{G} \alpha 12$, shed E-cadherin was identified in cell-conditioned medium by LC-MS/MS, the shedding probably being mediated by the protease ADAM10 (Xu et al. 2015). Like integrins, E-cadherin is a member of adherens junctions and is critical for proper epithelial cell-cell adhesion and maintenance of planar polarity (Leckband and de Rooij 2014). Thus, several reports indicate that the loss of PC-1 and PC-2 influences cell-cell and cell-matrix interactions, which probably contribute to cyst formation in ADPKD.

\section{ADPKD biomarkers}

Next to the analysis of potential disease mechanisms, MS has been used to develop prognostic and diagnostic biomarkers for ADPKD. The easier the accessibility of respective markers, the better their routine implementation. In the case of ADPKD, urine was tested extensively as a potential source of biomarkers. Urine is an easily accessible body fluid and harbors biologically and medically meaningful information in the form of peptides, proteins, or extracellular vesicles (EV) originating from the renal system (Rodriguez-Suarez et al. 2014). Several studies have described the use of the urine peptidome and proteome as a source of markers for urogenital diseases (Meguid El Nahas and Bello 2005; Schaub et al. 2004; Wittke et al. 2005). To define a particular biomarker, as being specific for a disease, molecules in the urine should be carefully discriminated regarding their origin. Urinary proteins can originate from the kidney, ureter, or the urinary bladder. Databases listing urinary proteins (Marimuthu et al. 2011), exosomal urinary proteins (Gonzales et al. 2009; Pisitkun et al. 2004) and ureter (Magdeldin et al. 2016), urinary bladder, prostate and kidney (Cui et al. 2013; Pinto et al. 2014; Wilhelm et al. 2014) proteins may help in identifying tissue-specific proteins.

In ADPKD, several urinary (and plasma) markers have been recently reported, e.g., NGAL, CCL2 (MCP-1), CD14, AVP (copeptin) and HAVCR1 (KIM-1; Bolignano et al. 2007; Kuehn et al. 2007; Meijer et al. 2010, 2011; Zheng et al. 2003). However, these markers have not made it into the clinic as yet and have also been reported to overlap with acute kidney injury patients and healthy controls thus raising concerns regarding their specificity (Kistler et al. 2013).

Urinary EVs represent a rich source of potential biomarkers and their concentration and their changing protein composition might uncover disease states. Indeed, changes in the protein content of urinary EVs during the progression of ADPKD and the accumulation of villin-1, periplakin and envoplakin have been observed (Salih et al. 2016). By using chemical labeling, urinary EVs have also been analyzed by comparing ADPKD patients and ADPKD patients under tolvaptan treatment (Pocsfalvi et al. 2015). Of the identified proteins, $1 \%$ have been characterized as novel urinary proteins and almost $70 \%$ of the quantified proteins have been found to be significantly altered relative to those of the healthy control group. Such a high degree of change is surprising and raises questions concerning data normalization and statistical analysis. 
As positive controls, PC-1, PC-2 and other calcium-binding proteins related to ciliary pathways are significantly depleted in EVs from ADPKD patients. Additionally, late stage ADPKD patients, with a lower glomerular filtration rate than the tolvaptan-treated group, show a higher number of differentially abundant proteins. GO term enrichment analysis of the data revealed upregulated proteins involved in membrane-to-membrane docking, the establishment or maintenance of apical/basal cell polarity and microtubule polymerization. Moreover, proteins involved in cytoskeletal organization are significantly upregulated in EVs of ADPKD patients. This agrees with the observation that cytoskeletal reorganization and polarity defects are often observed in cystogenesis.

In a complementary study, less than $0.5 \%$ of the urinary EV proteins differed significantly in abundance in samples of patients with a PKDI mutation (Hogan et al. 2015). This might be attributable to the set of included patients, as only young individuals $(<40$ years $)$ diagnosed with the PKD1 mutation were compared with healthy individuals by a label-free MS approach. The patients still demonstrated normal filtration rates. Young individuals with minor disease symptoms were chosen to limit the influences of fibrosis, inflammation and infection. Whereas PC-1 and PC-2 were both decreased in the individuals with the PKD1 mutation, transmembrane protein 2 (TMEM2), a homolog of fibrocystin, showed a more than two-fold higher abundance. Thus, the PC1/TMEM2 ratio of urinary EVs was inversely correlated with the height-adjusted kidney volume and the authors suggested that this could be used as a diagnostic tool for monitoring ADPKD.

Hypertension develops early in patients with ADPKD and is associated with the progression of the disease (Schrier 2009). Partial or complete loss of PKD1 or PKD2 expression is attended by abnormal vascular structure and function (Boulter et al. 2001). Further, $P K D 1^{-/}$cells are unable to transduce extracellular shearing into intracellular $\mathrm{Ca}^{2+}$ signaling and NO synthesis (Nauli et al. 2008). In ADPKD, the renin-angiotensin-aldosterone system (RAAS) is activated as a result of decreased NO production, cyst expansion and intrarenal ischemia (Chapman et al. 2010). With disease progression, further RAAS activation occurs and blood pressure increases. Treatments that block RAAS (ACE blockers) have been shown to slow down ADPKD progression (Jafar et al. 2005) but also have severe side effects (Mann et al. 2008). Thus, to study the effects of RAAS activation on primary human proximal tubular cells, the proteomes of angiotensinII (Ang-II)-treated and -nontreated cells were compared by using metabolic labeling in combination with MS (Konvalinka et al. 2013); 83 proteins were identified as differentially regulated in a SILAC-based proteomic approach, the most upregulated protein being heme oxygenase-1. In a follow-up study, SRM assays for the quantification of Ang-II- regulated proteins were developed that could potentially be used to monitor Ang-II activity in patients with chronic kidney disease (Konvalinka et al. 2016). Sample processing had to be optimized to counteract protein losses and to ensure proper protein digestion. In addition, protein/peptide modifications occurring either in vivo or as sample processing artifacts had to be taken into account. Interestingly, the authors found that the urine of ADPKD patients harbored fewer potential biomarkers compared with those of chronic kidney disease patients and a healthy control group, although mRNAs of respective target proteins were increased in renal cysts. They concluded that the cysts might have lost their contact and communication with tubules and thus, the respective proteins were not excreted to the same extent that they were produced.

Capillary electrophoresis (CE)-MS analysis of over 10,000 individual urine samples collected within the Consortium of Radiologic Imaging of Polycystic Kidney Disease (CRISP; https://www.niddkrepository.org/studies/crisp/) identified distinctive changes in urinary collagen-derived peptides, which could potentially be used as ADPKD biomarkers (Kistler et al. 2013). The authors speculated that cyst formation leads to a reorganization of the renal extracellular matrix and a decrease in regular collagen breakdown, finally resulting in a significant decrease of collagen-derived peptides in the urine of ADPKD patients. In agreement, this reduction is negatively correlated with the height-adjusted total kidney volume of respective individuals. Interestingly, peptides from fibrinogen alpha chain and keratin are more abundant in ADPKD samples, which is in agreement with the observations that fibronectin and keratin 19 accelerate renal cystogenesis and are associated with ADPKD (Mrug et al. 2008; Schieren et al. 2006).

The same source of samples and data were later used to identify a predictive peptidomic pattern for ADPKD and ESRD (Pejchinovski et al. 2016). Employing CE-MS, the authors detected 2247 urinary peptides in more than $40 \%$ of patients reaching ESRD and in respective controls. Twenty peptides were significantly altered in the excretion of ESRD cases versus controls. By LC-MS/MS, the amino acid sequence of 16 of these peptides could be identified, which were then used in a support vector machine-based approach to generate a prognostic biomarker model. The model managed to classify patients into low- or high-risk groups for ESRD. In silico analyses of potential proteolytic pathways involved in generating the prognostic peptides revealed nine proteases: in addition to cathepsins $\mathrm{D}, \mathrm{E}$ and $\mathrm{L}$, the following proteins were found: meprin A, MMP2, 3, 8 and 9 and pepsin A. MMPs are potentially involved in ADPKD by contributing to ECM turnover during cyst expansion (Berthier et al. 2008; Nakamura et al. 2000; Obermuller et al. 2001). Moreover, a shift in activity from cathepsin $\mathrm{L}$ to $\mathrm{D}$ and $\mathrm{E}$ was detected. Reduced proteolytic processing of Cux 1 by decreased cathepsin $\mathrm{L}$ 
activity is thought to contribute to cyst growth in murine $P k d 1^{-/}$cells (Alcalay et al. 2008). Cuxl, the murine homolog of human $C D P$, is a homeobox gene that represses the cyclin kinase inhibitors p21 and p27.

Although several potential ADPKD biomarkers have been identified by MS-based proteomics, to our knowledge, none of them is currently used in routine clinical diagnostics. Urine is widely appreciated to be a rich source for markers in renal diseases and individual peptides and proteins may mirror disease states. However, the discrimination of their origin, their availability and their exclusiveness to a particular phenomenon remains crucial. In most ADPKD studies, whether the suggested peptide/protein markers are ADPKD-specific or rather generally indicate renal injury remains unclear, e.g., the few studies that directly compared acute and chronic kidney injury identified similar sets of deregulated proteins. Next to disease specificity, the provision of technically robust SRM assays for biomarker quantification is a prerequsite, starting from sample generation and storage, in order to use them on a routine basis in clinical diagnostics. Current studies do consider the entire workflow and we are optimistic that robust assays will be available in the future.

\section{Concluding remarks}

Whereas the causative genes for ADPKD have been identified, the molecular mechanisms responsible for its clinical manifestation are still under debate. So far, the direct contribution of MS-based proteomic approaches to the identification of new molecular players in ADPKD has been humble. Altered glycan structures and perturbed cell-cell and cellmatrix interactions have been described. However, because of profound technical innovations, such as more sensitive instruments and streamlined sample processing protocols prior to LC-MS/MS analysis, we can expect increased input by MSbased approaches. In particular, the characterization of altered signaling events in ADPKD can massively benefit from stateof-the-art proteomic approaches.

In addition, improvements in the disease and therapy monitoring of ADPKD can be expected with the use of new MS developments. One of the greatest challenges remains the characterization of ADPKD-specific biomarkers. So far, the clinical implementation of potential biomarkers identified by MS has been rather disappointing. This is probably because of a lack of sensitivity and a restricted dynamic range of MS equipment, which only allows the routine identification and characterization of a limited number of proteins in single measurements. Moreover, the idea that a single protein might be sufficient to monitor a disease state is retrospectively rather naive. In contrast, new instruments allow the robust quantification of several thousand proteins in single measurements, even of low-abundant signal transducers. Thus, the characterization of robust biomarker panels comprising several proteins can be expected in the near future.

Acknowledgements This work was supported by the German Research Foundation (DFG) through the CRC 1140. J.D. is supported by the Swiss National Science Foundation (grant 31003A-166482/1). We apologize to colleagues whose work was not discussed because of limited space.

\section{Compliance with ethical standards}

Conflict of interest The authors declare no conflict of interest.

\section{References}

Aebersold R, Mann M (2016) Mass-spectrometric exploration of proteome structure and function. Nature 537:347-355

Alcalay NI, Sharma M, Vassmer D, Chapman B, Paul B, Zhou J, Brantley JG, Wallace DP, Maser RL, Vanden Heuvel GB (2008) Acceleration of polycystic kidney disease progression in cpk mice carrying a deletion in the homeodomain protein Cux1. Am J Physiol Renal Physiol 295:F1725-F1734

Bakalarski CE, Kirkpatrick DS (2016) A biologist's field guide to multiplexed quantitative proteomics. Mol Cell Proteomics 15: 1489-1497

Berthier CC, Wahl PR, Le Hir M, Marti HP, Wagner U, Rehrauer H, Wuthrich RP, Serra AL (2008) Sirolimus ameliorates the enhanced expression of metalloproteinases in a rat model of autosomal dominant polycystic kidney disease. Nephrol Dial Transplant 23:880889

Boehlke C, Kotsis F, Patel V, Braeg S, Voelker H, Bredt S, Beyer T, Janusch H, Hamann C, Godel M, Muller K, Herbst M, Hornung M, Doerken M, Kottgen M, Nitschke R, Igarashi P, Walz G, Kuehn EW (2010) Primary cilia regulate mTORC1 activity and cell size through Lkb1. Nat Cell Biol 12:1115-1122

Boerries M, Grahammer F, Eiselein S, Buck M, Meyer C, Goedel M, Bechtel W, Zschiedrich S, Pfeifer D, Laloe D, Arrondel C, Goncalves S, Kruger M, Harvey SJ, Busch H, Dengjel J, Huber TB (2013) Molecular fingerprinting of the podocyte reveals novel gene and protein regulatory networks. Kidney Int 83:1052-1064

Bolignano D, Coppolino G, Campo S, Aloisi C, Nicocia G, Frisina N, Buemi M (2007) Neutrophil gelatinase-associated lipocalin in patients with autosomal-dominant polycystic kidney disease. Am J Nephrol 27:373-378

Boulter C, Mulroy S, Webb S, Fleming S, Brindle K, Sandford R (2001) Cardiovascular, skeletal, and renal defects in mice with a targeted disruption of the Pkd1 gene. Proc Natl Acad Sci U S A 98:12174 12179

Bourmaud A, Gallien S, Domon B (2016) Parallel reaction monitoring using quadrupole-Orbitrap mass spectrometer: principle and applications. Proteomics 16:2146-2159

Bronsert P, Weisser J, Biniossek ML, Kuehs M, Mayer B, Drendel V, Timme S, Shahinian H, Kusters S, Wellner UF, Lassmann S, Werner M, Schilling O (2014) Impact of routinely employed procedures for tissue processing on the proteomic analysis of formalin-fixed paraffin-embedded tissue. Proteomics Clin Appl 8:796-804

Catherman AD, Skinner OS, Kelleher NL (2014) Top down proteomics: facts and perspectives. Biochem Biophys Res Commun 445:683693

Chang MY, Ong AC (2012) Mechanism-based therapeutics for autosomal dominant polycystic kidney disease: recent progress and future prospects. Nephron Clin Pract 120:c25-c34 
Chapman AB, Stepniakowski K, Rahbari-Oskoui F (2010) Hypertension in autosomal dominant polycystic kidney disease. Adv Chronic Kidney Dis 17:153-163

Collins AJ, Foley RN, Chavers B, Gilbertson D, Herzog C, Johansen K, Kasiske B, Kutner N, Liu J, St Peter W, Guo H, Gustafson S, Heubner B, Lamb K, Li S, Li S, Peng Y, Qiu Y, Roberts T, Skeans M, Snyder J, Solid C, Thompson B, Wang C, Weinhandl E, Zaun D, Arko C, Chen SC, Daniels F, Ebben J, Frazier E, Hanzlik C, Johnson R, Sheets D, Wang X, Forrest B, Constantini E, Everson S, Eggers P, Agodoa L (2012) United States renal data system 2011 annual data report: atlas of chronic kidney disease \& end-stage renal disease in the United States. Am J Kidney Dis 59(A7):e1-420

Cui Z, Yoshida Y, Xu B, Zhang Y, Nameta M, Magdeldin S, Makiguchi T, Ikoma T, Fujinaka H, Yaoita E, Yamamoto T (2013) Profiling and annotation of human kidney glomerulus proteome. Proteome Sci 11: 13

Diedrich B, Rigbolt KT, Roring M, Herr R, Kaeser-Pebernard S, Gretzmeier C, Murphy RF, Brummer T, Dengjel J (2017) Discrete cytosolic macromolecular BRAF complexes exhibit distinct activities and composition. EMBO J 36:646-663

Fagerberg L, Hallstrom BM, Oksvold P, Kampf C, Djureinovic D, Odeberg J, Habuka M, Tahmasebpoor S, Danielsson A, Edlund K, Asplund A, Sjostedt E, Lundberg E, Szigyarto CA, Skogs M, Takanen JO, Berling H, Tegel H, Mulder J, Nilsson P, Schwenk JM, Lindskog C, Danielsson F, Mardinoglu A, Sivertsson A, Feilitzen K von, Forsberg M, Zwahlen M, Olsson I, Navani S, Huss M, Nielsen J, Ponten F, Uhlen M (2014) Analysis of the human tissue-specific expression by genome-wide integration of transcriptomics and antibody-based proteomics. Mol Cell Proteomics 13:397-406

Gattone VH 2nd, Wang X, Harris PC, Torres VE (2003) Inhibition of renal cystic disease development and progression by a vasopressin V2 receptor antagonist. Nat Med 9:1323-1326

Gonzales PA, Pisitkun T, Hoffert JD, Tchapyjnikov D, Star RA, Kleta R, Wang NS, Knepper MA (2009) Large-scale proteomics and phosphoproteomics of urinary exosomes. J Am Soc Nephrol 20: 363-379

Grantham JJ (2008) Clinical practice. Autosomal dominant polycystic kidney disease. N Engl J Med 359:1477-1485

Gustafsson OJ, Arentz G, Hoffmann P (2015) Proteomic developments in the analysis of formalin-fixed tissue. Biochim Biophys Acta 1854: $559-580$

Hofherr A, Wagner C, Fedeles S, Somlo S, Kottgen M (2014) Nglycosylation determines the abundance of the transient receptor potential channel TRPP2. J Biol Chem 289:14854-14867

Hogan MC, Bakeberg JL, Gainullin VG, Irazabal MV, Harmon AJ, Lieske JC, Charlesworth MC, Johnson KL, Madden BJ, Zenka RM, McCormick DJ, Sundsbak JL, Heyer CM, Torres VE, Harris PC, Ward CJ (2015) Identification of biomarkers for PKD1 using urinary Exosomes. J Am Soc Nephrol 26:1661-1670

Huber TB, Walz G, Kuehn EW (2011) mTOR and rapamycin in the kidney: signaling and therapeutic implications beyond immunosuppression. Kidney Int 79:502-511

Jafar TH, Stark PC, Schmid CH, Strandgaard S, Kamper AL, Maschio G, Becker G, Perrone RD, Levey AS, ACE Inhibition in Progressive Renal Disease (AIPRD) Study Group (2005) The effect of angiotensin-converting-enzyme inhibitors on progression of advanced polycystic kidney disease. Kidney Int 67:265-271

Kistler AD, Serra AL, Siwy J, Poster D, Krauer F, Torres VE, Mrug M, Grantham JJ, Bae KT, Bost JE, Mullen W, Wuthrich RP, Mischak H, Chapman AB (2013) Urinary proteomic biomarkers for diagnosis and risk stratification of autosomal dominant polycystic kidney disease: a multicentric study. PLoS One 8:e53016

Konvalinka A, Zhou J, Dimitromanolakis A, Drabovich AP, Fang F, Gurley S, Coffman T, John R, Zhang SL, Diamandis EP, Scholey JW (2013) Determination of an angiotensin II-regulated proteome in primary human kidney cells by stable isotope labeling of amino acids in cell culture (SILAC). J Biol Chem 288:24834-24847

Konvalinka A, Batruch I, Tokar T, Dimitromanolakis A, Reid S, Song X, Pei Y, Drabovich AP, Diamandis EP, Jurisica I, Scholey JW (2016) Quantification of angiotensin II-regulated proteins in urine of patients with polycystic and other chronic kidney diseases by selected reaction monitoring. Clin Proteomics 13:16

Kreidberg JA, Donovan MJ, Goldstein SL, Rennke H, Shepherd K, Jones RC, Jaenisch R (1996) Alpha 3 beta 1 integrin has a crucial role in kidney and lung organogenesis. Development 122:3537-3547

Kuehn EW, Hirt MN, John AK, Muehlenhardt P, Boehlke C, Putz M, Kramer-Zucker AG, Bashkurov M, Weyer PS van de, Kotsis F, Walz G (2007) Kidney injury molecule 1 (Kim1) is a novel ciliary molecule and interactor of polycystin 2. Biochem Biophys Res Commun 364:861-866

Kusebauch U, Campbell DS, Deutsch EW, Chu CS, Spicer DA, Brusniak MY, Slagel J, Sun Z, Stevens J, Grimes B, Shteynberg D, Hoopmann MR, Blattmann P, Ratushny AV, Rinner O, Picotti P, Carapito C, Huang CY, Kapousouz M, Lam H, Tran T, Demir E, Aitchison JD, Sander C, Hood L, Aebersold R, Moritz RL (2016) Human SRMAtlas: a resource of targeted assays to quantify the complete human proteome. Cell 166:766-778

Lam MP, Venkatraman V, Xing Y, Lau E, Cao Q, Ng DC, Su AI, Ge J, Van Eyk JE, Ping P (2016) Data-driven approach to determine popular proteins for targeted proteomics translation of six organ systems. J Proteome Res 15:4126-4134

Leckband DE, Rooij J de (2014) Cadherin adhesion and mechanotransduction. Annu Rev Cell Dev Biol 30:291-315

Lehtonen S, Ora A, Olkkonen VM, Geng L, Zerial M, Somlo S, Lehtonen E (2000) In vivo interaction of the adapter protein CD2-associated protein with the type 2 polycystic kidney disease protein, polycystin-2. J Biol Chem 275:32888-32893

Loss1 P, Waterbeemd M van de, Heck AJ (2016) The diverse and expanding role of mass spectrometry in structural and molecular biology. EMBO J 35:2634-2657

Ma M, Tian X, Igarashi P, Pazour GJ, Somlo S (2013) Loss of cilia suppresses cyst growth in genetic models of autosomal dominant polycystic kidney disease. Nat Genet 45:1004-1012

Maes E, Broeckx V, Mertens I, Sagaert X, Prenen H, Landuyt B, Schoofs L (2013) Analysis of the formalin-fixed paraffin-embedded tissue proteome: pitfalls, challenges, and future prospectives. Amino Acids 45:205-218

Magdeldin S, Yamamoto K, Yoshida Y, Xu B, Zhang Y, Fujinaka H, Yaoita E, Yates JR 3rd, Yamamoto T (2014) Deep proteome mapping of mouse kidney based on OFFGel prefractionation reveals remarkable protein post-translational modifications. J Proteome Res 13:1636-1646

Magdeldin S, Hirao Y, Elguoshy A, Xu B, Zhang Y, Fujinaka H, Yamamoto K, Yates JR 3rd, Yamamoto T (2016) A proteomic glimpse into human ureter proteome. Proteomics 16:80-84

Mann JF, Schmieder RE, McQueen M, Dyal L, Schumacher H, Pogue J, Wang X, Maggioni A, Budaj A, Chaithiraphan S, Dickstein K, Keltai M, Metsarinne K, Oto A, Parkhomenko A, Piegas LS, Svendsen TL, Teo KK, Yusuf S, ONTARGET investigators (2008) Renal outcomes with telmisartan, ramipril, or both, in people at high vascular risk (the ONTARGET study): a multicentre, randomised, double-blind, controlled trial. Lancet 372:547-553

Marimuthu A, O’Meally RN, Chaerkady R, Subbannayya Y, Nanjappa V, Kumar P, Kelkar DS, Pinto SM, Sharma R, Renuse S, Goel R, Christopher R, Delanghe B, Cole RN, Harsha HC, Pandey A (2011) A comprehensive map of the human urinary proteome. J Proteome Res 10:2734-2743

Matsumoto M, Matsuzaki F, Oshikawa K, Goshima N, Mori M, Kawamura Y, Ogawa K, Fukuda E, Nakatsumi H, Natsume T, Fukui K, Horimoto K, Nagashima T, Funayama R, Nakayama K, 
Nakayama KI (2016) A large-scale targeted proteomics assay resource based on an in vitro human proteome. Nat Meth 14:251-258

Meguid El Nahas A, Bello AK (2005) Chronic kidney disease: the global challenge. Lancet 365:331-340

Meijer E, Boertien WE, Nauta FL, Bakker SJ, Oeveren W van, Rook M, Jagt EJ van der, Goor H van, Peters DJ, Navis G, Jong PE de, Gansevoort RT (2010) Association of urinary biomarkers with disease severity in patients with autosomal dominant polycystic kidney disease: a cross-sectional analysis. Am J Kidney Dis 56:883-895

Meijer E, Bakker SJ, Jagt EJ van der, Navis G, Jong PE de, Struck J, Gansevoort RT (2011) Copeptin, a surrogate marker of vasopressin, is associated with disease severity in autosomal dominant polycystic kidney disease. Clin J Am Soc Nephrol 6:361-368

Mrug M, Zhou J, Woo Y, Cui X, Szalai AJ, Novak J, Churchill GA, Guay-Woodford LM (2008) Overexpression of innate immune response genes in a model of recessive polycystic kidney disease. Kidney Int 73:63-76

Nakamura T, Ushiyama C, Suzuki S, Ebihara I, Shimada N, Koide H (2000) Elevation of serum levels of metalloproteinase-1, tissue inhibitor of metalloproteinase-1 and type IV collagen, and plasma levels of metalloproteinase-9 in polycystic kidney disease. Am J Nephrol 20:32-36

Nauli SM, Kawanabe Y, Kaminski JJ, Pearce WJ, Ingber DE, Zhou J (2008) Endothelial cilia are fluid shear sensors that regulate calcium signaling and nitric oxide production through polycystin-1. Circulation 117:1161-1171

Newby LJ, Streets AJ, Zhao Y, Harris PC, Ward CJ, Ong AC (2002) Identification, characterization, and localization of a novel kidney polycystin-1-polycystin-2 complex. J Biol Chem 277:20763-20773

Obermuller N, Morente N, Kranzlin B, Gretz N, Witzgall R (2001) A possible role for metalloproteinases in renal cyst development. Am J Physiol Renal Physiol 280:F540-F550

Ong AC, Harris PC (2005) Molecular pathogenesis of ADPKD: the polycystin complex gets complex. Kidney Int 67:1234-1247

Ostasiewicz P, Zielinska DF, Mann M, Wisniewski JR (2010) Proteome, phosphoproteome, and $\mathrm{N}$-glycoproteome are quantitatively preserved in formalin-fixed paraffin-embedded tissue and analyzable by high-resolution mass spectrometry. J Proteome Res 9:3688-3700

Pejchinovski M, Siwy J, Metzger J, Dakna M, Mischak H, Klein J, Jankowski V, Bae KT, Chapman AB, Kistler AD (2016) Urine peptidome analysis predicts risk of end-stage renal disease and reveals proteolytic pathways involved in autosomal dominant polycystic kidney disease progression. Nephrol Dial Transplant 32:487497

Perico N, Antiga L, Caroli A, Ruggenenti P, Fasolini G, Cafaro M, Ondei P, Rubis N, Diadei O, Gherardi G, Prandini S, Panozo A, Bravo RF, Carminati S, De Leon FR, Gaspari F, Cortinovis M, Motterlini N, Ene-Iordache B, Remuzzi A, Remuzzi G (2010) Sirolimus therapy to halt the progression of ADPKD. J Am Soc Nephrol 21:10311040

Pinto SM, Manda SS, Kim MS, Taylor K, Selvan LD, Balakrishnan L, Subbannayya T, Yan F, Prasad TS, Gowda H, Lee C, Hancock WS, Pandey A (2014) Functional annotation of proteome encoded by human chromosome 22. J Proteome Res 13:2749-2760

Pisitkun T, Shen RF, Knepper MA (2004) Identification and proteomic profiling of exosomes in human urine. Proc Natl Acad Sci U S A 101:13368-13373

Pocsfalvi G, Raj DA, Fiume I, Vilasi A, Trepiccione F, Capasso G (2015) Urinary extracellular vesicles as reservoirs of altered proteins during the pathogenesis of polycystic kidney disease. Proteomics Clin Appl 9:552-567

Qin S, Taglienti M, Nauli SM, Contrino L, Takakura A, Zhou J, Kreidberg JA (2010) Failure to ubiquitinate c-met leads to hyperactivation of mTOR signaling in a mouse model of autosomal dominant polycystic kidney disease. J Clin Invest 120:3617-3628
Rigbolt KT, Blagoev B (2012) Quantitative phosphoproteomics to characterize signaling networks. Semin Cell Dev Biol 23:863-871

Rigbolt KT, Zarei M, Sprenger A, Becker AC, Diedrich B, Huang X, Eiselein S, Kristensen AR, Gretzmeier C, Andersen JS, Zi Z, Dengjel J (2014) Characterization of early autophagy signaling by quantitative phosphoproteomics. Autophagy 10:356-371

Rinschen MM, Schermer B, Benzing T (2014a) Vasopressin-2 receptor signaling and autosomal dominant polycystic kidney disease: from bench to bedside and back again. J Am Soc Nephrol 25:1140-1147

Rinschen MM, Wu X, Konig T, Pisitkun T, Hagmann H, Pahmeyer C, Lamkemeyer T, Kohli P, Schnell N, Schermer B, Dryer S, Brooks BR, Beltrao P, Krueger M, Brinkkoetter PT, Benzing T (2014b) Phosphoproteomic analysis reveals regulatory mechanisms at the kidney filtration barrier. J Am Soc Nephrol 25:1509-1522

Rinschen MM, Pahmeyer C, Pisitkun T, Schnell N, Wu X, Maass M, Bartram MP, Lamkemeyer T, Schermer B, Benzing T, Brinkkoetter PT (2015) Comparative phosphoproteomic analysis of mammalian glomeruli reveals conserved podocin C-terminal phosphorylation as a determinant of slit diaphragm complex architecture. Proteomics 15:1326-1331

Rodriguez-Suarez E, Siwy J, Zurbig P, Mischak H (2014) Urine as a source for clinical proteome analysis: from discovery to clinical application. Biochim Biophys Acta 1844:884-898

Roitbak T, Ward CJ, Harris PC, Bacallao R, Ness SA, Wandinger-Ness A (2004) A polycystin-1 multiprotein complex is disrupted in polycystic kidney disease cells. Mol Biol Cell 15:1334-1346

Salih M, Demmers JA, Bezstarosti K, Leonhard WN, Losekoot M, van Kooten C, Gansevoort RT, Peters DJ, Zietse R, Hoorn EJ, DIPAK Consortium (2016) Proteomics of urinary vesicles links Plakins and complement to polycystic kidney disease. J Am Soc Nephrol 27: 3079-3092

Schaub S, Rush D, Wilkins J, Gibson IW, Weiler T, Sangster K, Nicolle L, Karpinski M, Jeffery J, Nickerson P (2004) Proteomic-based detection of urine proteins associated with acute renal allograft rejection. $\mathrm{J}$ Am Soc Nephrol 15:219-227

Schieren G, Rumberger B, Klein M, Kreutz C, Wilpert J, Geyer M, Faller D, Timmer J, Quack I, Rump LC, Walz G, Donauer J (2006) Gene profiling of polycystic kidneys. Nephrol Dial Transplant 21:1816 1824

Schrier RW (2009) Renal volume, renin-angiotensin-aldosterone system, hypertension, and left ventricular hypertrophy in patients with autosomal dominant polycystic kidney disease. J Am Soc Nephrol 20: 1888-1893

Serra AL, Poster D, Kistler AD, Krauer F, Raina S, Young J, Rentsch KM, Spanaus KS, Senn O, Kristanto P, Scheffel H, Weishaupt D, Wuthrich RP (2010) Sirolimus and kidney growth in autosomal dominant polycystic kidney disease. N Engl J Med 363:820-829

Sweeney WE Jr, Vigier RO von, Frost P, Avner ED (2008) Src inhibition ameliorates polycystic kidney disease. J Am Soc Nephrol 19:13311341

Tanca A, Abbondio M, Pisanu S, Pagnozzi D, Uzzau S, Addis MF (2014) Critical comparison of sample preparation strategies for shotgun proteomic analysis of formalin-fixed, paraffin-embedded samples: insights from liver tissue. Clin Proteomics 11:28

Torres VE, Chapman AB, Devuyst O, Gansevoort RT, Grantham JJ, Higashihara E, Perrone RD, Krasa HB, Ouyang J, Czerwiec FS, TEMPO 3:4 Trial Investigators (2012) Tolvaptan in patients with autosomal dominant polycystic kidney disease. N Eng1 J Med 367: $2407-2418$

Tyanova S, Temu T, Cox J (2016) The MaxQuant computational platform for mass spectrometry-based shotgun proteomics. Nat Protoc 11: 2301-2319

Uhlen M, Fagerberg L, Hallstrom BM, Lindskog C, Oksvold P, Mardinoglu A, Sivertsson A, Kampf C, Sjostedt E, Asplund A, Olsson I, Edlund K, Lundberg E, Navani S, Szigyarto CA, Odeberg J, Djureinovic D, Takanen JO, Hober S, Alm T, Edqvist 
PH, Berling H, Tegel H, Mulder J, Rockberg J, Nilsson P, Schwenk JM, Hamsten M, Feilitzen K von, Forsberg M, Persson L, Johansson F, Zwahlen M, Heijne G von, Nielsen J, Ponten F (2015) Proteomics. Tissue-based map of the human proteome. Science 347:1260419

Walz G, Budde K, Mannaa M, Nurnberger J, Wanner C, Sommerer C, Kunzendorf U, Banas B, Horl WH, Obermuller N, Arns W, Pavenstadt H, Gaedeke J, Buchert M, May C, Gschaidmeier H, Kramer S, Eckardt KU (2010) Everolimus in patients with autosomal dominant polycystic kidney disease. N Engl J Med 363:830840

Wilhelm M, Schlegl J, Hahne H, Gholami AM, Lieberenz M, Savitski MM, Ziegler E, Butzmann L, Gessulat S, Marx H, Mathieson T, Lemeer S, Schnatbaum K, Reimer U, Wenschuh H, Mollenhauer M, Slotta-Huspenina J, Boese JH, Bantscheff M, Gerstmair A, Faerber F, Kuster B (2014) Mass-spectrometry-based draft of the human proteome. Nature 509:582-587

Winter GE, Rix U, Carlson SM, Gleixner KV, Grebien F, Gridling M, Muller AC, Breitwieser FP, Bilban M, Colinge J, Valent P, Bennett KL, White FM, Superti-Furga G (2012) Systems-pharmacology dissection of a drug synergy in imatinib-resistant CML. Nat Chem Biol 8:905-912

Wittke S, Haubitz M, Walden M, Rohde F, Schwarz A, Mengel M, Mischak H, Haller H, Gwinner W (2005) Detection of acute tubulointerstitial rejection by proteomic analysis of urinary samples in renal transplant recipients. Am J Transplant 5:2479-2488

Xu JX, Lu TS, Li S, Wu Y, Ding L, Denker BM, Bonventre JV, Kong T (2015) Polycystin-1 and Galpha12 regulate the cleavage of Ecadherin in kidney epithelial cells. Physiol Genomics 47:24-32

Yuasa T, Takakura A, Denker BM, Venugopal B, Zhou J (2004) Polycystin-1L2 is a novel G-protein-binding protein. Genomics $84: 126-138$

Zahedi RP, Ueffing M, Sickmann A (2014) Proteomics - moving from inventory to personalized medicine? Proteomics 14:1953

Zhang AF, Wu SL, Jung Y, Qin S, Hancock WS, Kreidberg JA (2014) Identification of novel glycans with disialylated structures in alpha3 integrin from mouse kidney cells with the phenotype of polycystic kidney disease. J Proteome Res 13:4901-4909

Zhang Y, Muller M, Xu B, Yoshida Y, Horlacher O, Nikitin F, Garessus S, Magdeldin S, Kinoshita N, Fujinaka H, Yaoita E, Hasegawa M, Lisacek F, Yamamoto T (2015) Unrestricted modification search reveals lysine methylation as major modification induced by tissue formalin fixation and paraffin embedding. Proteomics 15:25682579

Zheng D, Wolfe M, Cowley BD Jr, Wallace DP, Yamaguchi T, Grantham JJ (2003) Urinary excretion of monocyte chemoattractant protein-1 in autosomal dominant polycystic kidney disease. J Am Soc Nephrol 14:2588-2595 